\title{
Heritability estimates of the position and number of facial hair whorls in Thoroughbred horses
}

\author{
Tamu Yokomori ${ }^{1}$, Teruaki Tozaki ${ }^{*}$ (1) , Hiroshi Mita ${ }^{3}$, Takeshi Miyake ${ }^{4}$, Hironaga Kakoi ${ }^{2}$, Yuki Kobayashi $^{1}$, \\ Kanichi Kusano ${ }^{5}$ and Takuya Itou ${ }^{1 *}$ (D)
}

\begin{abstract}
Objective: According to oral traditions of horse caretakers and trainers, the differences in the position and number of facial hair whorls may be associated with temperamental traits. Elucidating genetic background of facial hair whorls and its relationship to temperamental traits may promote more efficient breeding and maintenance of racehorses. In this study, we estimated heritabilities of the position and number of facial hair whorls in Japanese Thoroughbred horses.

Results: The number of facial hair whorls varied from one to four and heritability estimate in 4024 Thoroughbred horses was low $\left(h^{2}=0.160\right)$. The positions of facial hair whorls were categorized into high, medium, and low, based on their locations. This trait was estimated to have high heritability $\left(h^{2}=0.643\right)$ in 3782 Thoroughbred horses. These results indicated that a larger proportion of the variation in the studied population was due to genetic factors for facial hair whorls position. Because a similar result was also observed in another horse breed, Polish Konik horses, high heritability of facial hair whorl position may be characteristic of multiple horse breeds. We expect that these results will stimulate future studies to elucidate the relationship among temperamental traits and facial hair whorls in all horse breeds.
\end{abstract}

Keywords: Hair whorl, Heritability, Horse, Thoroughbred

\section{Introduction}

In general, horses have about 2-cm-long hairs on their body, and hair whorls exist on various body parts. The number and position of hair whorls have been used for individual identification of horses because they are quite individual. Almost all horses have one or more hair whorls on their forehead, and these facial hair whorls are classified into high, medium, and low, based on their position.

According to oral traditions among horse caretakers and trainers, facial hair whorls may be related to

\footnotetext{
*Correspondence: ttozaki@|rc.or.jp; itou.takuya@nihon-u.ac.jp

${ }^{1}$ Nihon University Veterinary Research Center, Fujisawa, Kanagawa

252-0880, Japan

${ }^{2}$ Genetic Analysis Department, Laboratory of Racing Chemistry, Utsunomiya, Tochigi 320-0851, Japan

Full list of author information is available at the end of the article
}

temperamental traits in horses $[1,2]$. Horses with a hair whorl at the low position might be difficult to handle, and horses with multiple facial hair whorls tend to fear novel items and environmental conditions [3]. In several recent studies, the relationships among facial hair whorls and behaviors were evaluated in horses. Rotation of facial hair whorl correlates with the turning response [4]. Right-lateralized horses have more clockwise facial hair whorls, whereas left-lateralized horses have more counter-clockwise ones [5].

Interestingly, heritability $\left(h^{2}\right)$ of facial hair whorl position has been estimated to be 0.753 in primitive Konik horse [6], which is a small and semi-feral horse in Poland. However, there have been no such studies in other breeds.

Thoroughbred is a breed produced by crossing Arabian stallions and native British mares at around seventeenth 
century, and then it underwent selection for superior racing abilities based on speed and stamina [7]. Therefore, while racing performance trait had been selected in their breeding history, temperament trait was not been selected and was variable in this breed. Several temperament phenotypes may affect not only the race performance but also the use of horses after retirement from racing.

In this study, we aimed to estimate heritabilities of the number and position of facial hair whorls in Japanese Thoroughbred horse populations. Elucidating the genetic background of facial hair whorls may inform horse breeders about temperamental traits, which, in turn, should optimize horse utility. We also hypothesized that positions of facial hair whorls are heritable in multiple horse breeds.

\section{Main text}

\section{Materials and methods} Thoroughbred horses

In this study, characteristics of 4845 Thoroughbred horses in Japan were analyzed. These horses were born in 2014 and registered with Japan Racehorse Association (JRA) as racehorses.

Multiple horses were excluded from the original population (4845 horses) for estimating heritability, because of maximum inputs in the GSTM program. Horses in small paternal half-sib families (under 20 or 10 horses at the position and number of facial hair whorls, respectively), and horses with the same phenotypes in their paternal half-sib families were excluded because of less informative.

\section{Phenotypic information}

Phenotypic information, namely the number and position of facial hair whorls, sex, and ancestors for three generations (13,057 horses), was collected from the Japan Racing Information System (JARIS), which is a database for JRA racehorses. As shown in Fig. 1, positions of facial hair whorls were classified based on Grandin et al. [8]. Phenotype frequency was manually counted and analyzed.

\section{Heritability estimation}

The traits (i.e., the number or position of whorls) were analyzed using non-linear categorical (threshold) trait models in Gibbs Sampling Threshold Model (GSTM) program [9]. To estimate heritability, the pedigree information of the Thoroughbred horses was traced back to three generations (maximum inputs in the GSTM program). The following model was used to perform a non-linear categorical trait analysis:

$$
L_{i j k}=S E X_{i}+u_{k}+e_{i j k}
$$

where $L_{i j k}$ is the normally distributed liability assumed with threshold $t$ behind the categorical phenotypes $Y_{i j k}$ of the categorized traits. The category values of $Y_{i j k}$ begin with 1 . For example, in the case of binary phenotypes, the

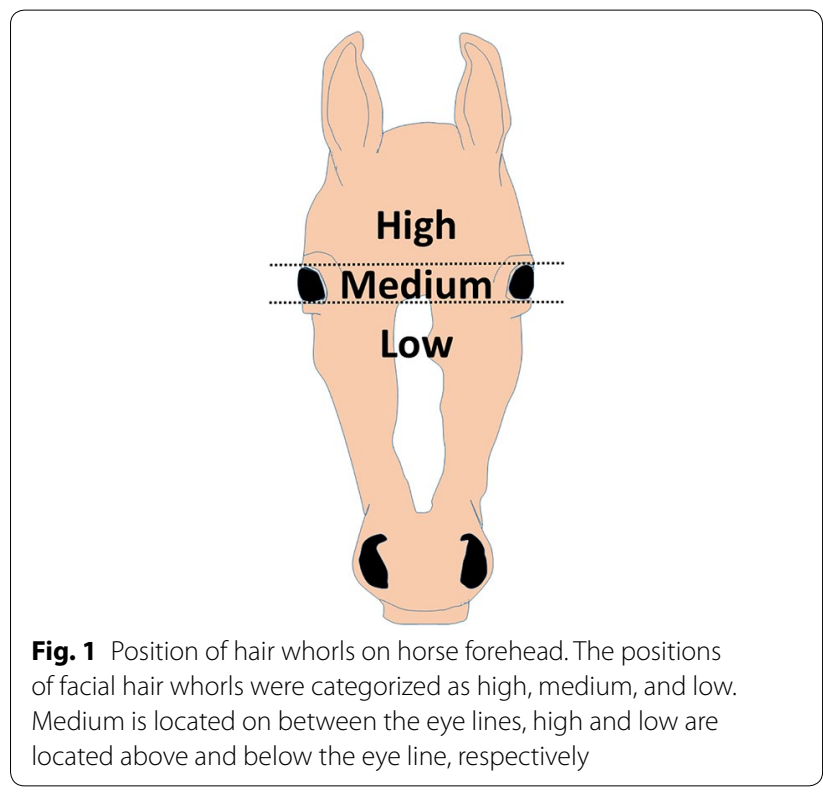

relationship between $L_{i j k}, Y_{i j k}$, and $t$ is as follows: $Y_{i j k}=1$ $\left(L_{i j k} \leq t\right)$ and $Y_{i j k}=2\left(t<L_{i j k}\right) . S E X_{i}$ is the effect of the $i$ th sex, $u_{k}$ is the breeding value of the $k$ th individual [i.e., it follows normal distribution $\left[N\left(\mathbf{0}, \mathbf{A} \sigma^{2}{ }_{u}\right)\right]$, and $e_{i j k}$ is the residual effect $\left[N\left(\mathbf{0}, \mathbf{I}^{2}{ }_{e}\right)\right]$. In these two distributions, $\mathbf{A}$ is the numerator relationship matrix, $\sigma^{2}{ }_{u}$ is the additive genetic variance, $\mathbf{I}$ is the identity matrix, and $\sigma_{e}^{2}$ is the residual variance.

Heritability $\left(h^{2}\right)$ is then defined as $\sigma_{u}^{2} /\left(\sigma^{2}{ }_{u}+\sigma^{2}\right)$. The total number of Gibbs samplings with GSTM program was $1,050,000$, with a burn-in period of 50,000, which was sufficiently large for convergence of the parameters estimated in the present study.

\section{Results}

\section{Phenotype of facial hair whorls}

As shown in Table 1, Thoroughbred racehorses had one to four whorls. The majority of them had one $(81.07 \%)$ or two

\section{Table 1 Frequency of hair whorl phenotypes in Thoroughbred} horses

\begin{tabular}{lcc}
\hline Number of hair whorls & Counts & Percentage \\
\hline 1 & 3928 & 81.07 \\
2 & 904 & 18.69 \\
3 & 12 & 0.25 \\
4 & 1 & 0.02 \\
\hline Position of hair whorl & Counts & Percentage \\
\hline High & 2702 & 55.77 \\
Medium & 1111 & 22.93 \\
Low & 115 & 2.37 \\
Multiple & 917 & 18.93 \\
\hline
\end{tabular}


Table 2 Heritability estimates of hair whorl in Thoroughbred horses

\begin{tabular}{llll}
\hline & Mode & Mean \pm SD & $\mathbf{9 5 \% ~ C l}$ \\
\hline Number & 0.160 & $0.192 \pm 0.061$ & $0.093-0.332$ \\
Position & 0.643 & $0.660 \pm 0.097$ & $0.478-0.852$ \\
\hline
\end{tabular}

(18.65\%) whorls. Accordingly, whorl positions were analyzed depending on whether the horse had one (81.07\%) and multiple (18.93\%) whorls. Furthermore, 55.77\% horses had one whorl at the high position, $22.93 \%$-at the medium position, and $2.37 \%$-at the low position.

\section{Heritability estimates}

By eliminating horses in small paternal half-sib families and horses with the same phenotypes as in their paternal half-sib families, 4024 horses that had one (3280 horses) or two (744 horses) whorls and their 10,765 ancestors were used for estimating heritability of facial whorl number. We calculated heritability estimate of whorl number to be 0.160 (Table 2).

By eliminating horses in small paternal half-sib families and horses with the same phenotypes as in their paternal half-sib families, 3782 horses with one whorl in the high (2556 horses), medium (1111 horses), and low (115 horses) position, and their 10,592 ancestors were used for estimating heritability of facial whorl position. According to our calculations, heritability estimate of whorl position was 0.643 (Table 2).

The posterior probabilities of the heritability of the whorl number and position showed that those heritability estimates clearly differed from zero and generally distributed normally (Additional file 1: Figure S1), indicating that these are heritable traits.

\section{Discussion}

In this study, high heritability $\left(h^{2}=0.643\right)$ of facial hair whorl position was demonstrated in Thoroughbred horses. A similar study in the Konik horse population also reported high heritability of this trait $\left(h^{2}=0.753\right)$ [6]. Because high heritability estimates were obtained independently in different breeds, it can be concluded that a large proportion of the variation in facial hair whorl positions in horses is due to genetic factors.

In contrast, heritability estimate of facial hair whorl number was low $\left(h^{2}=0.160\right)$, although $95 \% \mathrm{CI}$ of the heritability did not include "zero", indicating that variation of facial hair whorl number is affected largely by environmental but also by genetic factors.

High heritability of optimal race distance has been reported in a Thoroughbred population $\left(h^{2}=0.51\right)$ [10] and myostatin (MSTN) gene was identified as a single causative gene of this effect by a genome-wide association study (GWAS) using single nucleotide polymorphisms [11]. Moderate heritability of racing performance (win vs. non-win) was estimated in a Japanese Thoroughbred population $\left(h^{2}=0.34\right)$ [12], and a genomic region spanning MSTN was also identified by GWAS by using microsatellites [13]. Hence, it is expected that causative genes underlying facial hair whorl position may be identified in future by GWAS. While heritability of hair whorl number was low, GWAS may also clarify causative genes because the trait may be qualitative (i.e., mainly controlled by a major gene).

Various methods of horse character evaluation have ever been suggested but these may be biased depending on the evaluator [14]. In addition, it is difficult to distinguish between inborn and potentially acquired temperament [15]. Therefore, isolating candidate genes may lead to the development of a genetic test for temperament because of the relatively high heritability of facial hair whorl position. It may also optimize life after racehorse retirement and improve horse welfare.

\section{Conclusion}

In conclusion, our results suggested that genetic factors contribute more to the variability of facial hair whorl position rather than to that of whorl number. These findings could be useful for designing a rational plan of racehorse management. We also expect that these results will stimulate future studies to elucidate the relationship among temperamental traits and facial hair whorls in all horse breeds.

\section{Limitations}

It should be noted that heritability values were estimated using sample populations, in which horses with the same phenotypes as those in their paternal half-sib family and horses in small paternal half-sib families were eliminated.

\section{Additional file}

Additional file 1: Figure S1. Posterior probabilities (distribution) of heritability estimates for the number (a) and position (b) of hair whorls. Horizontal axis: heritability values; vertical axis: posterior probability with corresponding heritability value.

\section{Abbreviations}

GSTM: Gibbs Sampling Threshold Model; GWAS: genome-wide association study; JARIS: Japan Racing Information System; JRA: Japan Racehorse Association; MSTN: myostatin.

\section{Acknowledgements}

We would like to thank the Japan Racing Association for providing phenotypic data and pedigree information. 


\section{Authors' contributions}

TT and TI conceived and designed the experiment; TY, TT, TM, YK, and TI performed the experiments; HM, HK, and KK collected phenotypic data and pedigree information; TY and TT drafted the manuscript; HM, HK, and KK provided critical comments and helped with the discussion of the results; all authors reviewed the manuscript and approved the submission of the final version. All authors read and approved the final manuscript.

\section{Funding}

The authors received no specific funding for the current study.

\section{Availability of data and materials}

All the data supporting the findings are contained within the manuscript.

Ethics approval and consent to participate

In this study, animal experiments was not performed.

\section{Consent for publication}

Not applicable.

\section{Competing interests}

The authors declare that they have no competing interests.

\section{Author details}

${ }^{1}$ Nihon University Veterinary Research Center, Fujisawa, Kanagawa 252-0880, Japan. ${ }^{2}$ Genetic Analysis Department, Laboratory of Racing Chemistry, Utsunomiya, Tochigi 320-0851, Japan. ${ }^{3}$ Clinical Veterinary Medicine Division, Equine Research Institute, Japan Racing Association, Shimotsuke, Tochigi 329-0412, Japan. ${ }^{4}$ Comparative Agricultural Sciences, Graduate School of Agriculture, Kyoto University, Sakyo, Kyoto 606-852, Japan. ${ }^{5}$ Racehorse Hospital Ritto Training Center, Japan Racing Association, 1028 Misono, Ritto, Shiga 520-3085, Japan.

Received: 7 May 2019 Accepted: 13 June 2019

Published online: 18 June 2019

\section{References}

1. Sumiński S. Konie Oficerskie w Armji (Officers' Horses in the Army). Toruń: Nakład Autorski Czcionkami Pomorskiej Drukarni Rolniczej; 1930 (in Polish).

2. Tellington-Jones $L$, Talor S. Die Persőnalichleit Ihres Pferdes. Stuttgart: Franckh-Kosmos Verlags-GmbH and Co.; 1995.

3. Górecha-Bruzda A, Golonka M, Chruszczewski MH, Jezierski T. A note on behaviour and heart rate in horses differing in facial hair whorl. Appl Anim Behav Sci. 2007;105:244-8.
4. Shivley CB, Grandin T, Deesing MJ. Behavioral laterality and facial hair whorls in horses. J Equine Vet Sci. 2016;44:62-6.

5. Morphy J, Arkins S. Facial hair whorls (trichoglyphs) and the incidence of motor laterality in the horse. Behav Process. 2008;79:7-12.

6. Górecka A, Sloniewski K, Golonka M, Jaworski Z, Jezierski T. Heritability of hair whorl position on the forehead in Konik horses. J Anim Breed Genet. 2006;123:396-8.

7. Sharman P, Wilson AJ. Racehorses are getting faster. Biol Lett. 2015:11:20150310.

8. Grandin T, Deesing MJ, Struthers JJ, Swinker AM. Cattle with hair whorl patterns above the eyes are more behaviorally agitated during restraint. Appl Anim Behav Sci. 1995;46:117-23.

9. Miyake T, Oki H, Nishiura A, Ibi T, Sasaki Y. Computer program for genetic analysis with Gibbs sampling for threshold model, GSTM. J Anim Breed Genet. 1999;38.

10. Hill EW, McGivney BA, Rooney MF, Katz LM, Parnell A, MacHugh DE. The contribution of myostatin (MSTN) and additional modifying genetic loci to race distance aptitude in Thoroughbred horses racing in different geographic region. Equine Vet J. 2019. https://doi.org/10.1111/evj.13058.

11. Hill EW, McGivney BA, Gu J, Whiston R, Machugh DE. A genome-wide SNP-association study confirms a sequence variant ( 9.66493737 C > T) in the equine myostatin (MSTN) gene as the most powerful predictor of optimum racing distance for Thoroughbred racehorses. BMC Genomics. 2010;11:552.

12. Tozaki T, Miyake T, Kakoi H, Gawahara H, Hirota K, Nakano Y, Kurosawa M. Heritability estimates for racing performance in Japanese thoroughbred racehorses using linear and non-linear model analysis. J Anim Breed Genet. 2012;129:402-8.

13. Tozaki T, Miyake T, Kakoi H, Gawahara H, Sugita S, Hasegawa T, Ishida N, Hirota K, Nakano Y. A genome-wide association study for racing performances in Thoroughbreds clarifies a candidate region near the MSTN gene. Anim Genet. 2010;2:28-35.

14. Momozawa Y, Kusunose R, Kikusui T, Takeuchi Y, Mori Y. Assessment of equine temperament questionnaire by comparing factor structure between two separate surveys. Appl Anim Behav Sci. 2005;92:77-84.

15. Momozawa Y, Ono T, Sato F, Kikusui T, Takeuchi Y, Mori Y, Kusunose R. Assessment of equine temperament by a questionnaire survey to caretakers and evaluation of its reliability by simultaneous behaviour test. Appl Anim Behav Sci. 2003;84:127-38.

\section{Publisher's Note}

Springer Nature remains neutral with regard to jurisdictional claims in published maps and institutional affiliations.

Ready to submit your research? Choose BMC and benefit from:

- fast, convenient online submission

- thorough peer review by experienced researchers in your field

- rapid publication on acceptance

- support for research data, including large and complex data types

- gold Open Access which fosters wider collaboration and increased citations

- maximum visibility for your research: over $100 \mathrm{M}$ website views per year

At $\mathrm{BMC}$, research is always in progress.

Learn more biomedcentral.com/submissions 